Research Article

\title{
Constitutive Model of Solid Backfill Materials and Numerical Simulation of Overburden Movement and Deformation in Backfill Mining
}

\author{
Chao Ma $\mathbb{D}^{\mathrm{D}},{ }^{1}$ Lianying Zhang $\mathbb{D}^{1},{ }^{1}$ Bing $\mathrm{Li} \mathbb{C}^{\mathrm{D}},{ }^{1}$ and Xianbiao Mao $\mathbb{( D}^{2}$ \\ ${ }^{1}$ Xuzhou University of Technology, Xuzhou 221000, China \\ ${ }^{2}$ School of Mechanics and Civil Engineering, China University of Mining and Technology, Xuzhou 221008, China \\ Correspondence should be addressed to Lianying Zhang; zhanglianying@126.com
}

Received 26 November 2020; Revised 27 December 2020; Accepted 18 January 2021; Published 29 January 2021

Academic Editor: Junfei Zhang

Copyright (c) 2021 Chao Ma et al. This is an open access article distributed under the Creative Commons Attribution License, which permits unrestricted use, distribution, and reproduction in any medium, provided the original work is properly cited.

Solid backfill mining is an efficient and environmental-friendly coal mining technology, which can effectively solve the problems of coal gangue pollution, water resource loss, and surface subsidence. Based on the mechanical behavior of backfill materials in the compaction process, volume strain was used to express the deformation modulus, and a constitutive model of backfill materials was proposed in this study. The ABAQUS UMAT was used to develop the numerical calculation subroutine of the model. Finally, the rationality of the model was verified that simulated stress-strain curves of the backfill materials during the compaction process agree well with experiments. Based on the proposed constitutive model, the influence of three factors (the initial compaction rate of the filling body, the mining height, and the mining depth) on the key strata and surface subsidence was analyzed systematically. The results show that the initial compaction rate and the height of coal seams have significant influences on surface subsidence. When the thickness of topsoil is only changed and the structural composition and lithology of overburden are not changed, the mining depth has little influence on surface subsidence, but a significant influence on surface subsidence range. The influence of mining height and mining depth on the deformation of key strata of overburden and surface subsidence is approximately linear, while the influence of the initial compaction rate is nonlinear.

\section{Introduction}

The rapid development of China's economy relies heavily on coal resources. With the gradual reduction of resources, the intensity of coal mining is gradually increasing. In traditional coal mining, coal gangue will be generated during the roadway excavation and coal washing, accounting for about $15 \%$ of the total weight. The accumulation of coal gangues has caused a series of environmental problems [1-3], such as land occupation, water pollution, and air pollution after spontaneous combustion [4-7]. In addition, coal mining can also cause the fracture of key strata [8-11], resulting in the loss of groundwater resources [12-14] and surface subsidence $[15,16]$. Solid backfill mining is an environmental coal mining technology, in which coal gangue is used as the main filling body to replace the underground coal resources
$[17,18]$. This method can be used to consume the existing coal gangue, alleviate the environmental problems caused by the accumulation of coal gangue, reduce the disturbance of coal mining on overburden, and prevent the fracture of key strata and greatly reduce the surface subsidence [19-21].

In solid backfill mining, backfill materials are mainly composed of coal gangue, fly ash, and other industrial wastes. The mechanical properties of backfill materials determine the control ability of backfill mining on the movement and deformation of overburden. At present, the studies on mechanical behavior of backfill materials have been systematically studied, including the axial stress-strain curve of the compacted cylinder [22, 23], the creep relaxation [24], the influence of particle size ratio on the mechanical behavior [1], and the influence of confining pressure and lateral pressure on mechanical properties [25]. 
Under the axial compression in cylinder, the stress-strain curve of the backfill materials presents typical nonlinear characteristics, which can be accurately fitted by polynomial negative exponential functions [26].

Due to the resistance of the filling body to overburden, the mining strength of solid backfill mining is small. The finite element method based on continuum mechanics can be used to numerically simulate the movement and deformation of overburden rock, so as to evaluate the influence of different backfill mining schemes on key strata and surface subsidence. Through the numerical simulation, Huang Yanli et al. analyzed the control effect of different compaction rates of the filling body on the strata movement and surface subsidence during the solid backfill mining [27]. Zha Jianfeng et al. used numerical simulation method to study the influence of gangue backfill as double yield model and elastic model on strata movement. However, the backfill materials are considered as elastic materials in the abovementioned studies, and the compaction process of gangue filling into goaf under the action of overburden cannot be correctly reflected [28]. Li Meng proposed a backfill material model considering pressure coefficient and performed the numerical simulation of overburden movement and deformation characteristics based on FLAC3D software [29]. However, in this constitutive model of backfill materials, the influence of lateral stress was not considered in the axial deformation modulus. Based on the negative exponential function curve of backfill material, Zhang et al. proposed a negative exponential function model of backfill mining and predicted the strain and deformation law of overburden during backfill mining by the numerical simulation in ABAQUS software [30]. However, the effect of lateral stress in the compaction experiment was considered in this model, and the compaction effect of the compaction machine on backfill materials after backfill mining was not considered in the simulation. As a result, the mechanical behavior of backfill materials cannot be accurately described.

According to the continuum theory, experimental results, and mechanical characteristics of solid backfill materials, a constitutive model of backfill materials was proposed based on the relationship between volume strain and deformation modulus. The platform of ABAQUS UMAT was used, then the numerical development of the model was performed, and the influence of the initial compaction rate of backfill materials, mining height, and mining depth on the movement and deformation law of overburden was systematically analyzed.

\section{Mechanical Properties of Solid Backfill Materials}

The physical and mechanical properties of solid backfill materials are the important basis for the analysis of overburden movement in solid backfill mining. Solid backfill materials are generally composed of broken coal gangue, fly ash, loess, and other industrial wastes in the form of granular materials. The mechanical property test of solid backfill material was carried out with the compaction experimental device, as shown in Figure 1. During the experiment, the backfill materials were placed inside the cylinder, and then the piston was pressed by the mechanical testing machine to compact the backfill materials. During the compaction process, the compression force and displacement of the machine were collected, and the loading rate was quasilinear loading. After the experiment, the axial stress and strain of backfill materials were calculated through the pressure and displacement of the testing machine. Figure 2 shows the stress-strain curves of the four kinds of broken rock during the compaction process. It can be seen that the stress-strain curve of the backfill materials changes in a nonlinear way during the compaction process. At the initial compressive deformation, the resistance of backfill material is low because there are numerous of gaps in the backfill materials. The stress increases slightly at the initial compressive deformation but its growing rate rises gradually at subsequent deformation. With the increase of strain, the increasing range of stress gradually increases. By using regression analysis, some scholars proposed that the stress-strain relationship of broken rock is an exponential function [31]:

$$
\sigma=A e^{B \varepsilon}
$$

where $\sigma$ and $\varepsilon$ are the axial stress and strain of fractured rock mass; $A$ and $B$ are regression coefficients.

\section{Establishment and Numerical Implementation of Constitutive Model of Solid Backfill Materials}

3.1. Constitutive Model of Solid Backfill Material. The backfill materials of solid backfill mining are relatively loose, and there are a lot of voids in the material. Therefore, the solid backfill material is not an ideal elastic body, but a porous discontinuous medium with elasticity, plasticity, and viscosity. When the finite element method is used to calculate the surface subsidence law after backfill mining, the stressstrain relationship of backfill materials during the loading process should be established to effectively reveal the resistance of backfill materials to the deformation of overburden. Firstly, based on the physical and mechanical properties of backfill materials during the backfill mining, the following assumptions are put forward for backfill materials:

(1) Each component in the backfill materials is evenly distributed, and the backfill materials are isotropic materials.

(2) Backfill materials are always compacted and assumed to be a continuum;

(3) Backfill materials are always under compression in three directions in goaf, and the yield and failure of backfill materials are not considered.

Based on the abovementioned hypothesis, the constitutive model of backfill materials is the constitutive relation of elastic materials:

$$
\sigma=\mathrm{D}: \varepsilon
$$



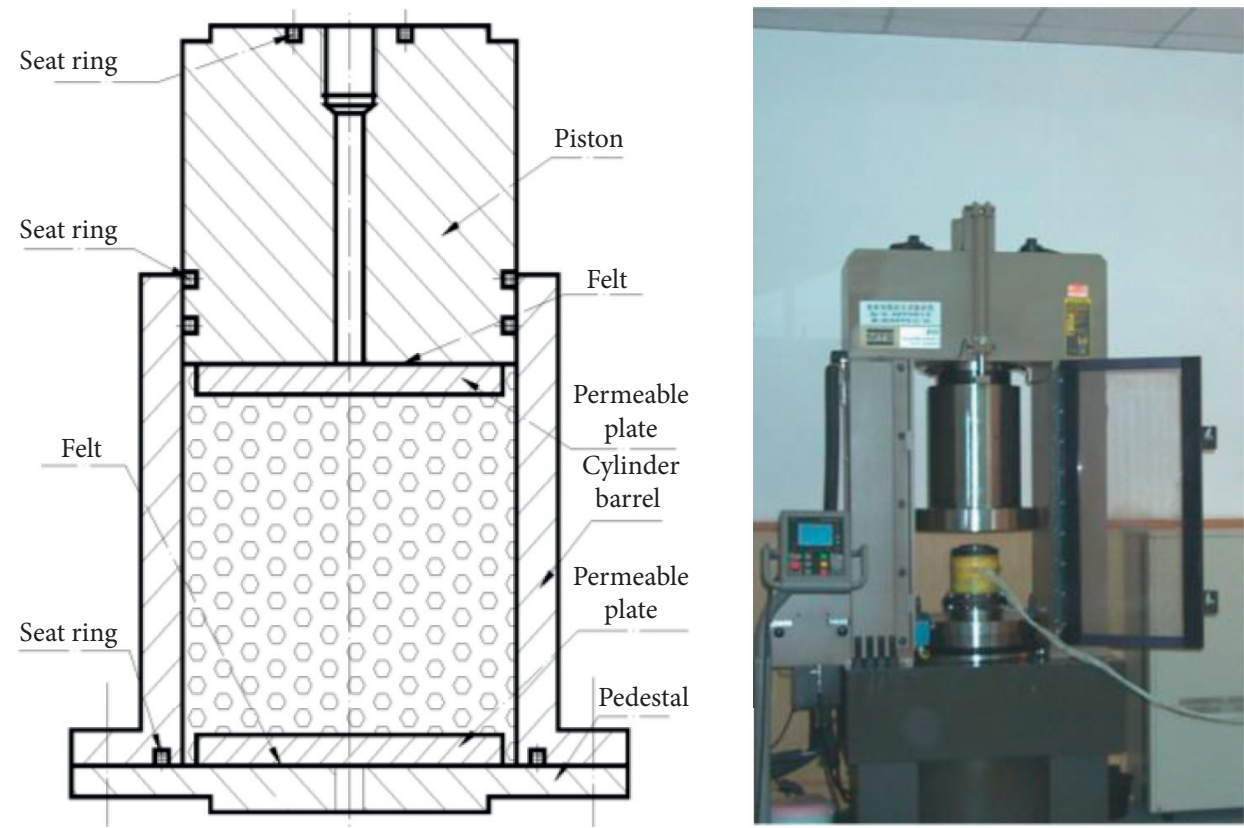

FIGURE 1: Experimental devices for the compaction of solid backfill materials [31].

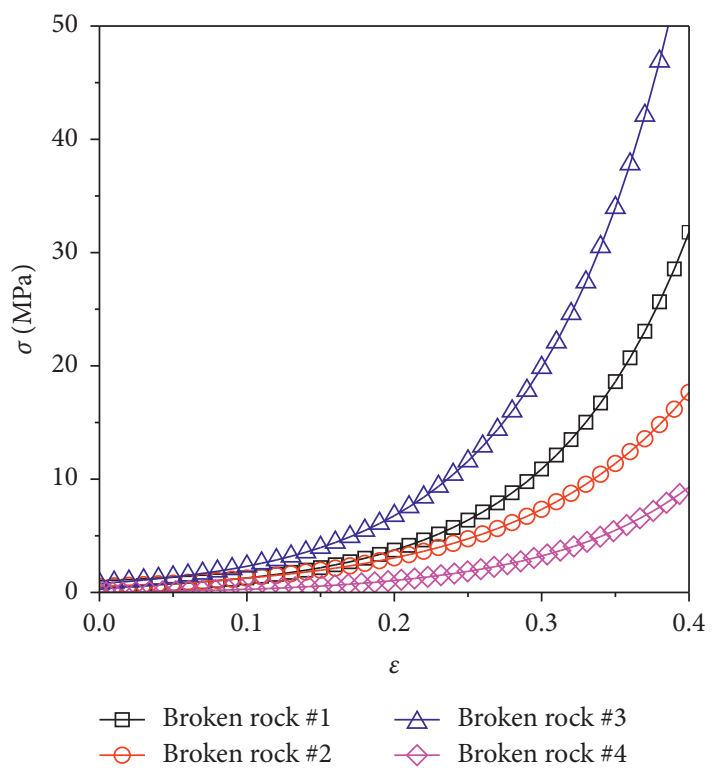

FIGURE 2: Stress-strain curves of various broken rocks [31].

where $\sigma, \mathcal{\varepsilon}$, and $\mathbf{D}$ are the stress tensor, strain tensor, and fourth-order elastic tensor of backfill materials, respectively. Besides, $\mathbf{D}$ is related to deformation modulus $E$ and Poisson's ratio $\mu$. As the stress and deformation of backfill materials are nonlinear in the process of compaction, it is necessary to find out the relationship between deformation modulus $E$, Poisson's ratio $\mu$, and strain, so as to further determine the constitutive model of backfill materials. The Poisson's ratio $\mu$ is difficult to be determined because the backfill material is loose, so Poisson's ratio $\mu$ is assumed to be a constant. According to the generalized Hooke law, the stress-strain relationship of backfill material in the compaction experiment is as follows:

$$
\sigma_{z}=\frac{E}{1+\mu} \mathcal{E}_{z}+\frac{E \mu}{(1+\mu)(1-2 \mu)} \mathcal{E}_{v},
$$

where $\sigma_{z}$ and $\varepsilon_{z}$ are the stress and strain in the compression direction, respectively; $\varepsilon v$ is the volume strain, and $\varepsilon_{v}=\varepsilon_{x}+\varepsilon_{y}+\varepsilon_{z}$. In the compaction process, because the rigidity of the cylinder is large, $\varepsilon_{x}$ and $\varepsilon_{y}$ are far less than $\varepsilon_{z}$. Therefore, $\varepsilon_{v} \approx \varepsilon_{z}$, and the above formula can be further simplified as follows:

$$
\sigma_{z}=m E \varepsilon_{z},
$$

where $m$ is a constant related to Poisson's ratio. Combined with equation (1), equation (5) can be obtained:

$$
E=\frac{A e^{B \varepsilon_{z}}}{m \varepsilon_{z}}=\frac{A e^{B \varepsilon_{v}}}{m \varepsilon_{v}} .
$$

By introducing equation (5) into equation (1), the constitutive relation of backfill materials can be obtained.

3.2. Numerical Simulation. Based on ABAQUS UMAT, the subroutine of solid backfill materials is developed. The calculation flow (Figure 3 ) is as follows:

(1) At the beginning of the incremental step, the basic parameters of the material are given, including parameters $A, B$, and $\mu$ and initial volume strain $\varepsilon_{v i n i}$. After backfill materials are filled into the goaf, the compaction machine of filling hydraulic support tamps the filling body to ensure that the backfill material has a certain initial compaction rate. The compaction rate is the ratio of the compacted volume to the initial volume, and the relationship between the compaction rate and the volume strain is as follows: 


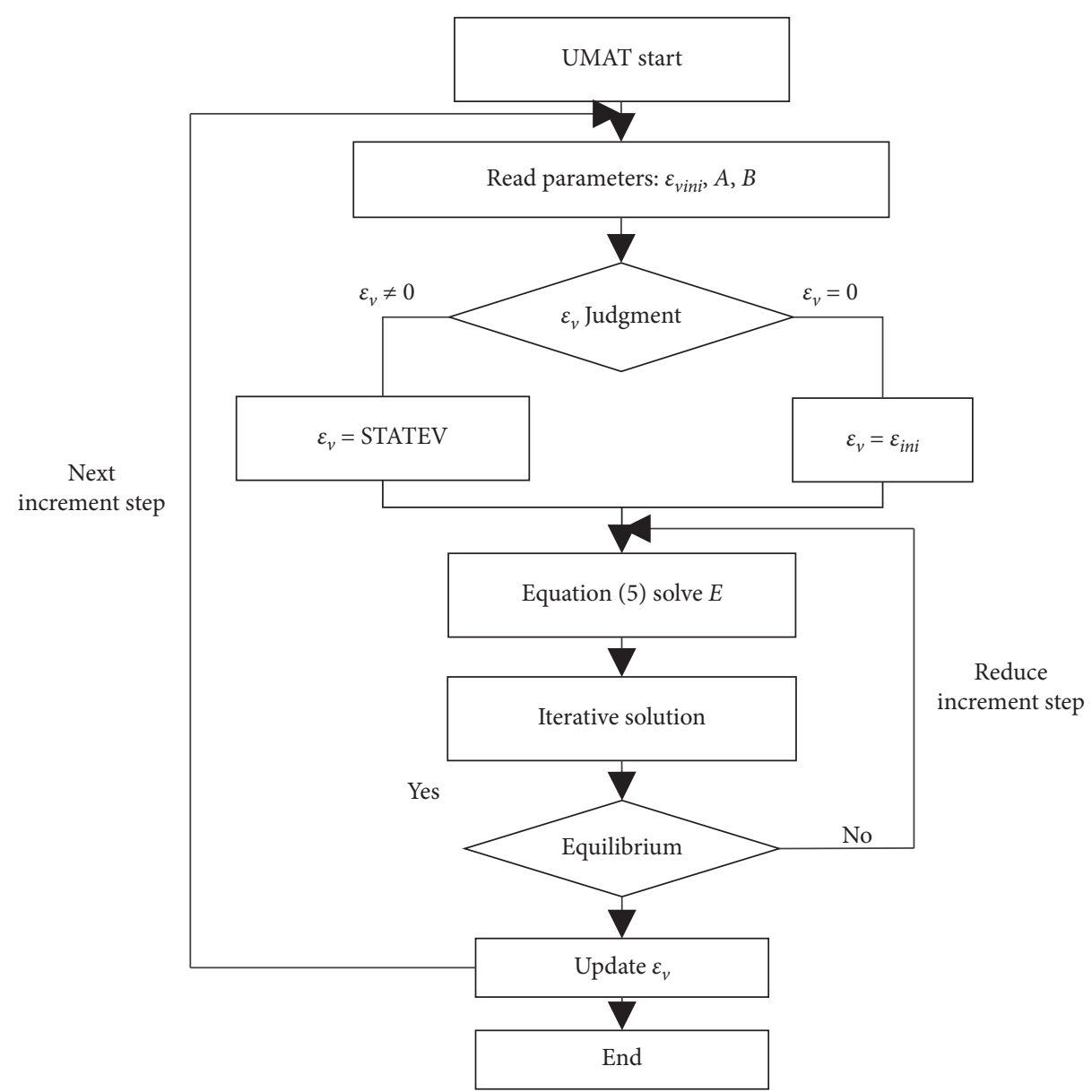

Figure 3: Flow chart of backfill material model development.

$$
\varepsilon_{v i n i}=\frac{V_{s}-V_{y s}}{V_{s}}=1-K_{y \sin \mathrm{i}} \text {, }
$$

where $V_{y s}$ is the volume of backfill materials after compaction, $V_{s}$ is the initial volume, and $K_{y \sin \mathrm{i}}$ is the initial compaction rate.

(2) Because ABAQUS calls the same subroutine every time, the volume strain of the model is different in the first load step and the subsequent load step. Then, the volume strain should be judged before starting the program. If $\varepsilon_{x}+\varepsilon_{y}+\varepsilon_{z}=0$, the volume strain is the initial volume strain $\varepsilon_{i n i}$; if $\varepsilon_{x}+\varepsilon_{y}+\varepsilon_{z} \neq 0$, the volume strain is the volume strain stored in the previous loading step for updating the deformation modulus.

(3) The deformation modulus is updated by equation (5), and then the Jacobian matrix is updated, and the current volume strain is stored.

(4) After the end of the incremental step, ABAQUS main program can automatically perform the convergence judgment. If it converges, the next incremental step is entered; if not, the incremental step is reduced until it converges.
3.3. Model Validation. The compaction process of backfill material is spatially axisymmetric, and the central axis of the cylinder is the axis of symmetry. Therefore, the finite element model is established by using the axisymmetric element in ABAQUS, as shown in Figure 4. In the experiment, the inner wall of the cylinder is coated with lubricating oil. Therefore, friction-free contact is established between the cylinder and the filling body and between the piston and the filling body to simulate the interaction between the backfill materials and the cylinder. The bottom of the model restricts the vertical displacement and limits the horizontal displacement of the symmetry axis. The loading mode is displacement loading with the size of $U_{z}=60.75 \mathrm{~mm}$, i.e., $\varepsilon_{z}=0.45$. The elastic modulus and Poisson's ratio of steel used for cylinder and piston are $220 \mathrm{GPa}$ and 0.3 , respectively. The parameters of backfill materials are shown in Table 1 .

Figures 5 and 6, respectively, show the stress-strain curves and elastic modulus-volume strain curves of fractured shale, mudstone, coal, and sandstone. It can be seen that the experimental values and numerical simulation values of the stress-strain curves and elastic modulus-volume strain curves of the four broken rock masses are consistent. It indicates that the backfill material model developed by UMAT is reliable and can be 


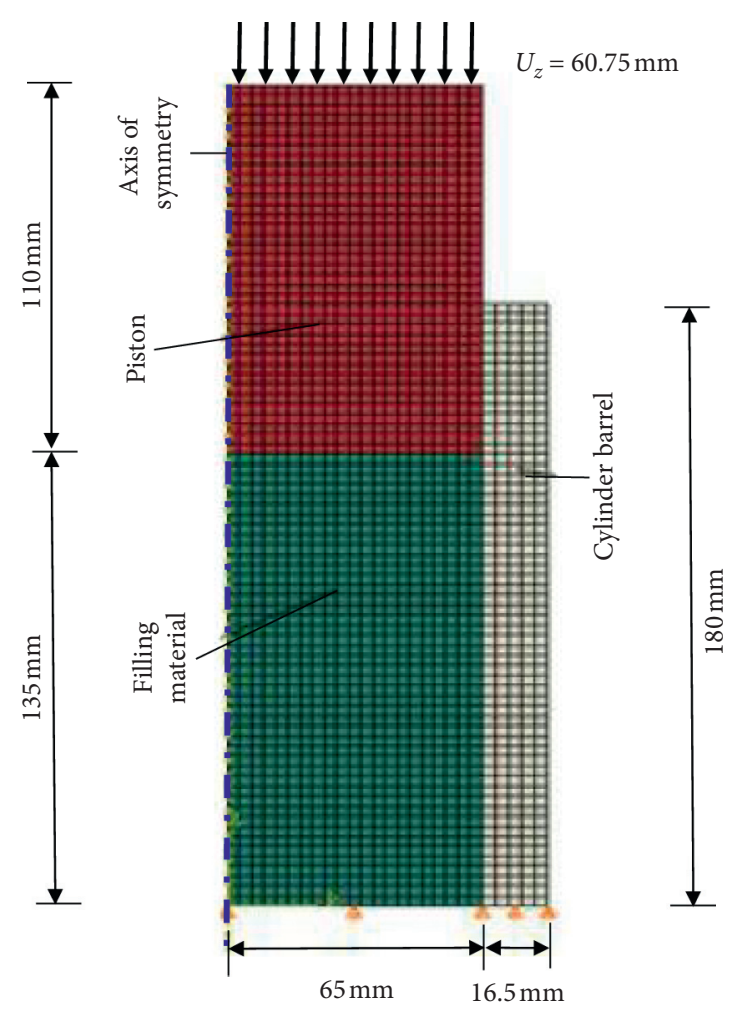

FIGURE 4: Numerical calculation model.

TABLE 1: Material parameters of the filling body.

\begin{tabular}{|c|c|c|c|c|}
\hline \multirow{2}{*}{ Broken rock number } & \multicolumn{4}{|c|}{ Parameters } \\
\hline & $A$ & $B$ & $\varepsilon_{\text {vini }}$ & $\mu$ \\
\hline Broken rock \#1 & $0.526 \times 10^{6}$ & 8.78 & 0 & 0.22 \\
\hline Broken rock \#2 & $0.438 \times 10^{6}$ & 10.71 & 0 & 0.21 \\
\hline Broken rock \#3 & $0.785 \times 10^{6}$ & 10.75 & 0 & 0.23 \\
\hline Broken rock \#4 & $0.1442 \times 10^{6}$ & 10.31 & 0 & 0.22 \\
\hline
\end{tabular}

used for the numerical simulation of overburden deformation during the solid backfill mining.

\section{Numerical Calculation Model of Overburden Movement and Deformation Law in Solid Backfill Mining}

The engineering geological conditions of the third mining area in No. 12 coal mine of Pingdingshan Coal Group Co., Ltd., was taken as the background, and the large-scale general finite element calculation software ABAQUS was used as the analysis and calculation platform. According to the geological conditions and the symmetry characteristics of the working face, the numerical mechanical model of the plane strain was established, as shown in Figure 7. The model size is $1000 \mathrm{~m} \times 380 \mathrm{~m}$; the horizontal displacement is constrained on both sides of the model, and the vertical displacement is constrained at the bottom. The rock layer exerts a body force of $\rho g$, where $\rho$ is the density and $g$ is the acceleration of gravity. The Mohr-Coulomb model of ABAQUS is used for the parameters of each stratum, and the physical and mechanical parameters are shown in Table 2. Considering the factors of calculation accuracy and calculation time, the mesh near the coal seam is refined. The model is divided into 4085 grids, as shown in Figure 7. The mechanical properties of the filling body play an important role in controlling the overburden movement of the working face. According to the stress-strain test results of the solid backfill material, broken rock \#4 is selected as the backfill material, and the material parameters are shown in Table 2.

To study the law of overburden deformation and surface subsidence under the condition of backfill mining, the influence of the initial compaction rate of the filling body, mining height, and mining depth on overburden deformation and surface subsidence is mainly considered in the model; the numerical calculation scheme is shown in Table 3.

\section{Results and Discussion}

Figure 8 shows the vertical displacement contour map of overburden under various initial compaction rates of the backfill. The horizontal dimension in the figure is $350 \mathrm{~m}$ to 


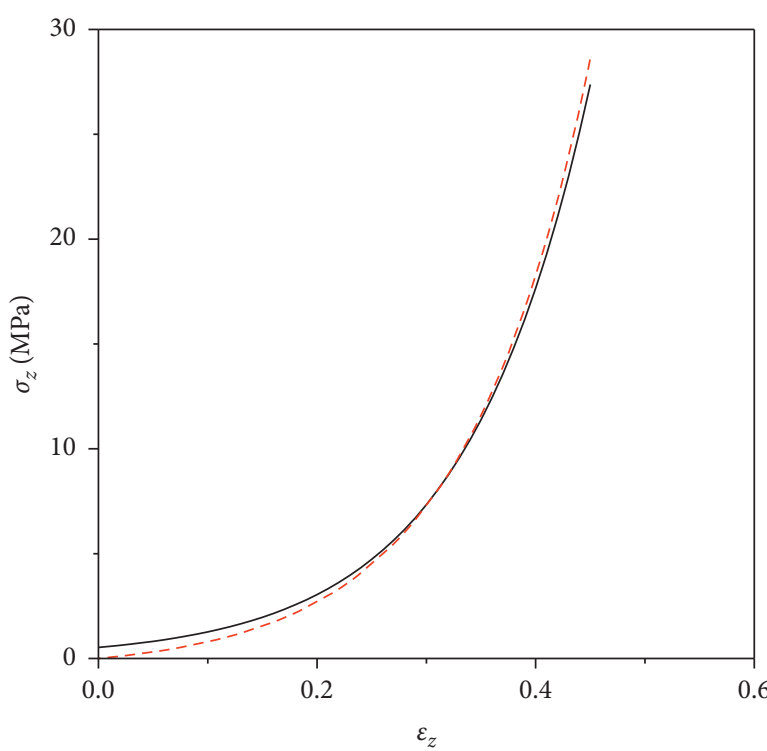

- EXP

-. SIM

(a)

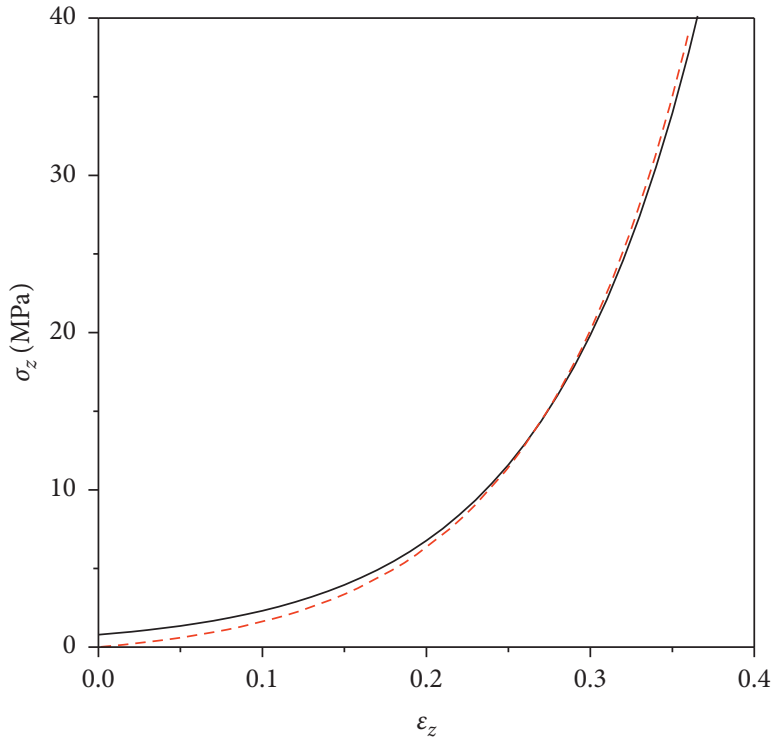

EXXP
$\ldots$ SIM

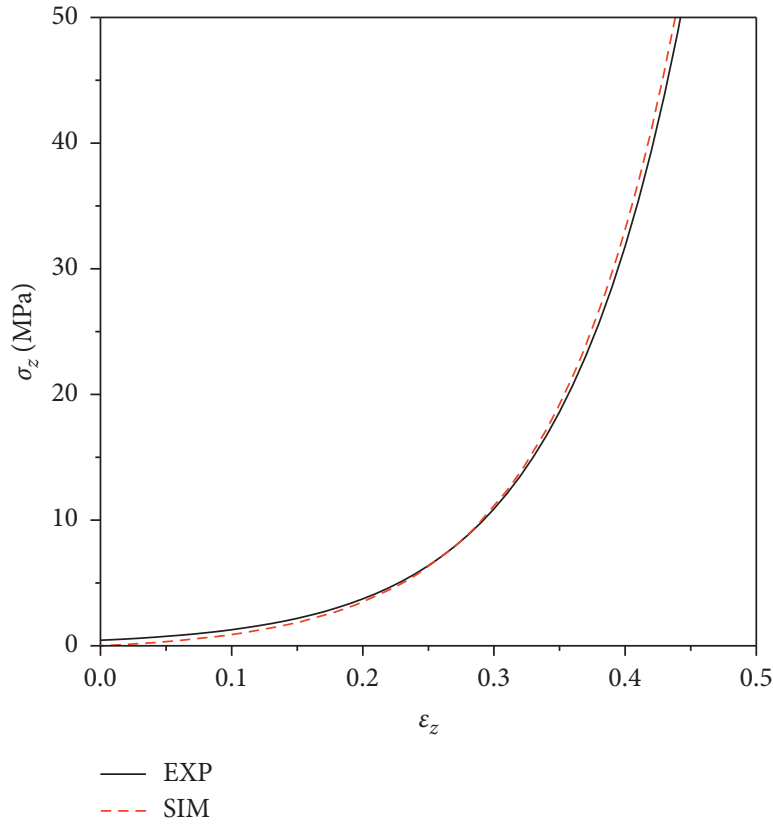

(b)

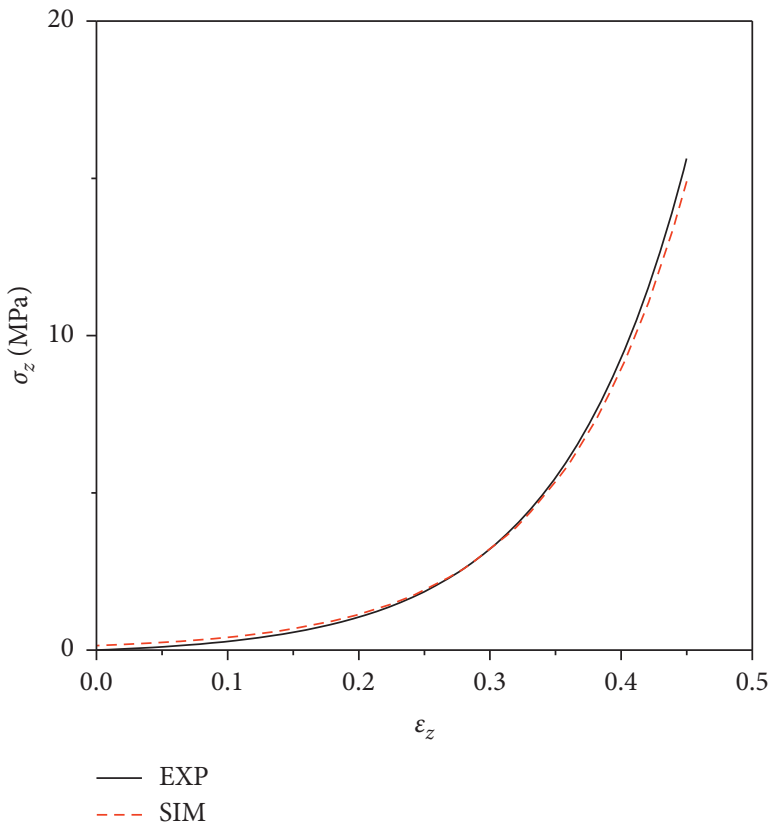

(d)

FiguRE 5: Comparison of stress-strain curves of various broken rocks in experiment and simulation. (a), (b), (c), and (d) represent broken rock \#1-4.

the right of the middle of the working face, and the vertical dimension is $380 \mathrm{~m}$ from the bottom of the model to the surface. It can be seen that with the decrease of the initial compaction rate, the small displacement contour (0.05) of overburden gradually moves to the surface, and the scope of overburden between adjacent isolines gradually increases. Figure 9(a) shows the subsidence curve of the main key strata. When the initial compaction rate of filling decreases from 0.95 to 0.85 , the deformation of the key strata of overburden gradually decreases, and the reduction amplitude is significant. Figures 9(b) and 9(c) show the surface subsidence curve and the curve of the maximum surface subsidence varying with the initial compaction rate of the filling body. It can be seen that, with the increase of the initial compaction rate, the surface subsidence decreases obviously. Similar to the deformation law of the key strata of overburden, when the initial compaction ratio of filling decreases from 0.95 to 0.85 , the surface subsidence gradually decreases, 


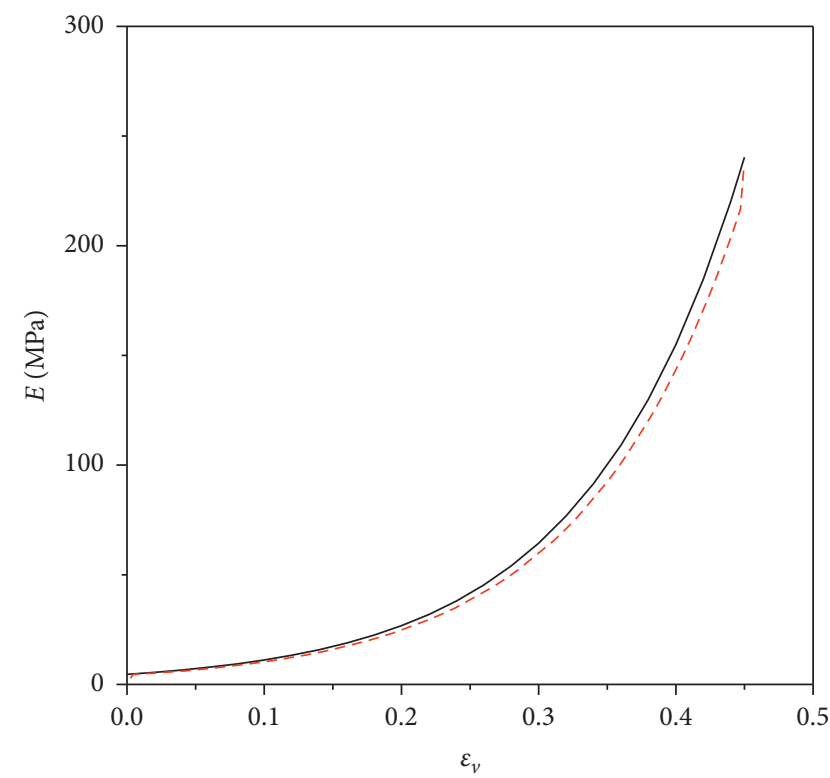

EXP

- - SIM

(a)

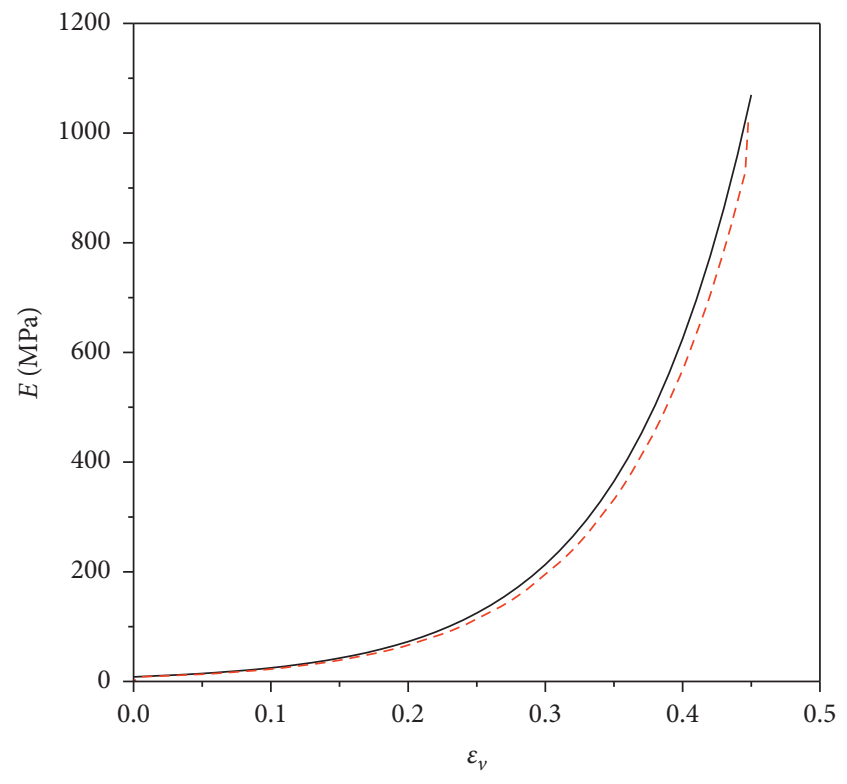

- EXP

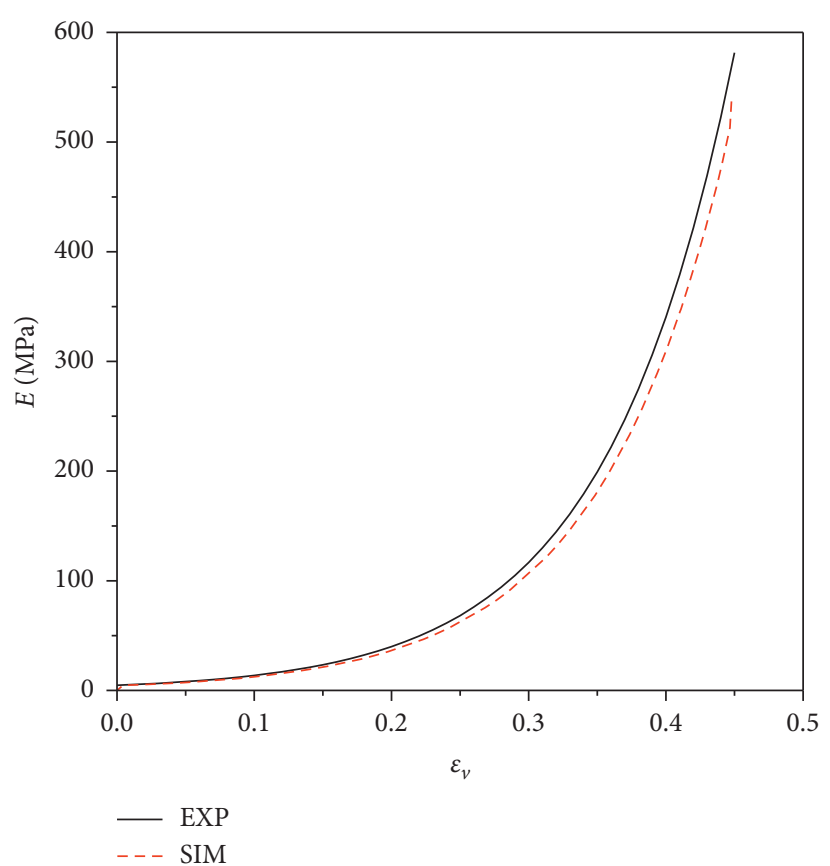

(b)

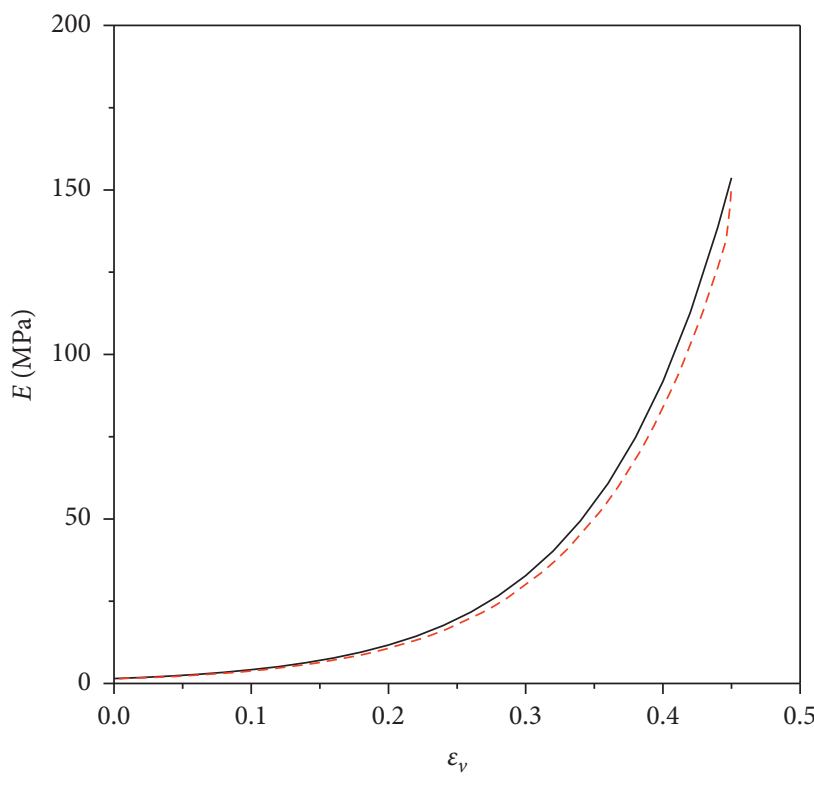

- EXP

(c)

(d)

FIGURE 6: Elastic modulus curves of various broken rocks in experiment and simulation changing with volume strain. (a), (b), (c), and (d) represent broken rock \#1-4.

and the reduction amplitude is obvious. As shown in Figures 9(a) and 9(b), the surface subsidence curve is similar to that of the main key strata, but the surface subsidence value under the same compaction rate of the filling body is smaller than that of the main key strata, because the stress redistribution occurs in the overburden after mining, and the main key strata are close to the stope, which will cause great disturbance after mining. In addition, the main key strata and surface subsidence have a nonlinear change law with the initial compaction rate, because the initial compaction rate reflects the initial volume strain of the backfill material, which has a nonlinear relationship with the deformation modulus of the backfill material.

There is a complex influence of mining depth on the surface subsidence and overburden deformation, and the structural composition and lithologic characteristics of 


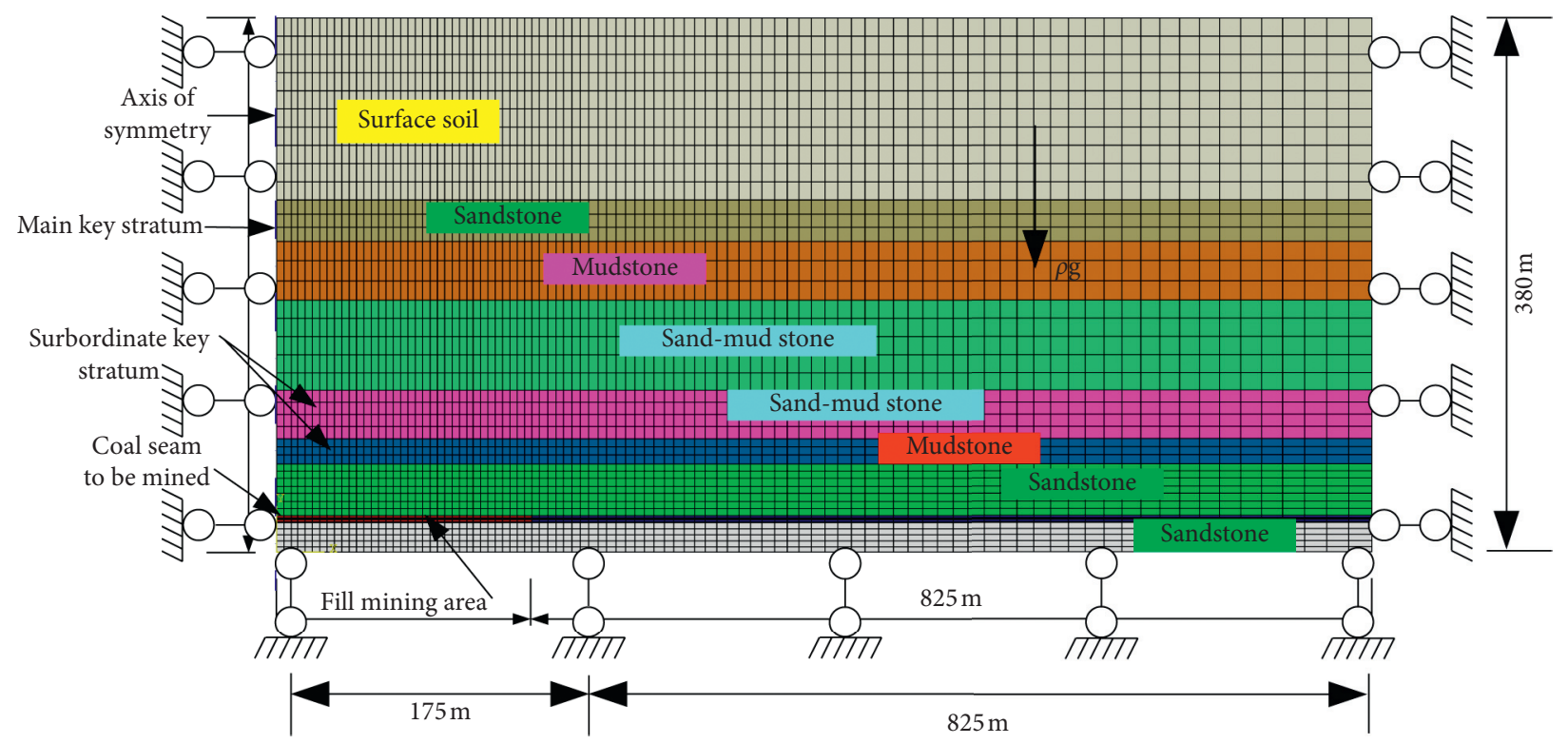

Figure 7: The numerical calculation model.

Table 2: Physical and mechanical parameters of the model.

\begin{tabular}{|c|c|c|c|c|c|c|}
\hline Lithology & $\begin{array}{c}\text { Thickness } \\
(\mathrm{h} / \mathrm{m})\end{array}$ & $\begin{array}{c}\text { Density } \\
\left(\rho / \mathrm{kg} / \mathrm{m}^{3}\right)\end{array}$ & $\begin{array}{c}\text { Bulk modulus, } \\
K(\mathrm{GPa})\end{array}$ & $\begin{array}{c}\text { Shear modulus, } \\
G(\mathrm{GPa})\end{array}$ & $\begin{array}{c}\text { Cohesive } \\
\text { force }(c / \mathrm{MPa})\end{array}$ & $\begin{array}{c}\text { Internal friction } \\
\text { angle }\left(\varphi /^{\circ}\right)\end{array}$ \\
\hline Surface soil & 133 & 1300 & 5.6 & 1.85 & 1.5 & 26 \\
\hline Sandstone & 29 & 2500 & 22.7 & 11.7 & 8.3 & 32 \\
\hline Mudstone & 42 & 2400 & 8.3 & 3.8 & 6.1 & 30 \\
\hline $\begin{array}{l}\text { Sand- } \\
\text { mudstone }\end{array}$ & 64 & 2300 & 11.4 & 5.8 & 6.5 & 31 \\
\hline $\begin{array}{l}\text { Sand- } \\
\text { mudstone }\end{array}$ & 34 & 2300 & 15.2 & 7.8 & 6.4 & 31 \\
\hline Mudstone & 18 & 2400 & 8.3 & 3.8 & 6.1 & 30 \\
\hline Sandstone & 37 & 2500 & 16.7 & 10 & 8.3 & 32 \\
\hline \#2 coal seam & 3.3 & 1800 & 4.17 & 1.09 & 2.1 & 28 \\
\hline Sandstone & 30 & 2500 & 16.7 & 10 & 8.3 & 32 \\
\hline
\end{tabular}

TABLE 3: Numerical calculation scheme.

\begin{tabular}{lccc}
\hline Scheme no. & Initial compaction rate $(\%)$ & Mining height $(\mathrm{m})$ & Mining depth $(\mathrm{m})$ \\
\hline 1 & $95,90,85,80,75,70$ & 3.3 & 380 \\
2 & 85 & $2.5,3.3,3.5,4.0,4.5,5.0$ & 380 \\
3 & 85 & 3.3 & $350,400,450,500,550,600$ \\
\hline
\end{tabular}

overburden have significant influence on overburden deformation. To study the influence of mining depth on the deformation movement of overburden in backfill mining, only the thickness of topsoil is changed. The thickness of topsoil is set as $133 \mathrm{~m}, 183 \mathrm{~m}, 233 \mathrm{~m}, 283 \mathrm{~m}, 333 \mathrm{~m}$, and $383 \mathrm{~m}$, and the corresponding mining depth is $350 \mathrm{~m}, 400 \mathrm{~m}$, $450 \mathrm{~m}, 500 \mathrm{~m}, 550 \mathrm{~m}$, and $600 \mathrm{~m}$. When the structural composition and lithologic characteristics of overburden are unchanged, the initial compaction rate Kys $=0.85$ and the mining height $h=3.3 \mathrm{~m}$. Figure 10 shows the vertical displacement nephogram of overburden rock when the mining depths are $350 \mathrm{~m}, 450 \mathrm{~m}, 550 \mathrm{~m}$, and $600 \mathrm{~m}$, respectively, and the horizontal dimensions in the figure are $350 \mathrm{~m}, 450 \mathrm{~m}$, $550 \mathrm{~m}$, and $600 \mathrm{~m}$, respectively. It can be seen that with the increase of mining depth, the same displacement contour gradually moves to the right, and the deformation range of overburden in stope increases gradually. Figure 11(a) shows the subsidence curve of the main key strata and the variation curve of the subsidence peak value of the main key strata with the mining depth $H$. It can be seen that with the increase of mining depth, the subsidence of the main key layer increases. When the mining depth $H$ increases from $350 \mathrm{~m}$ to 


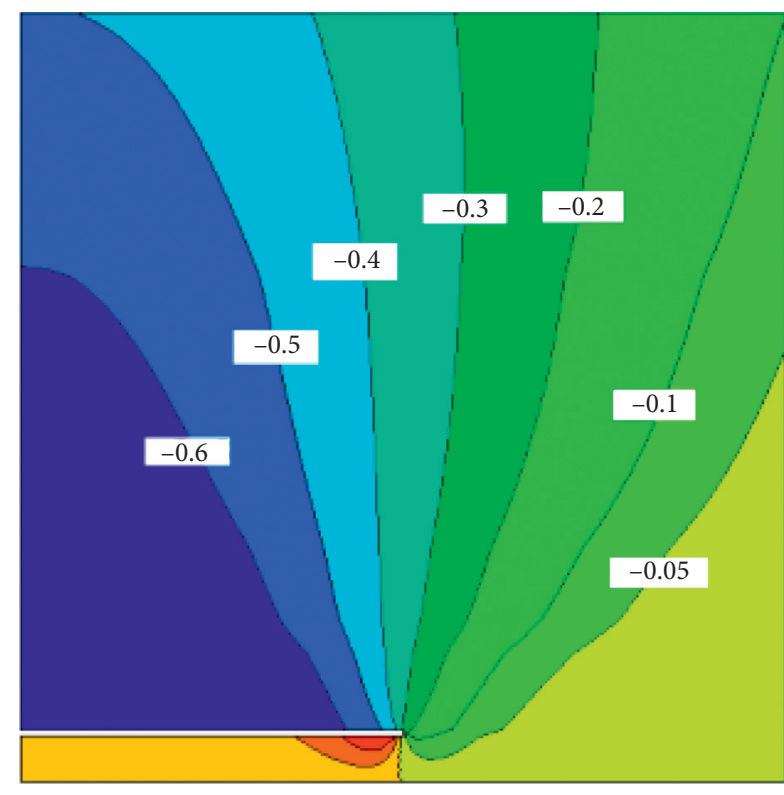

(a)

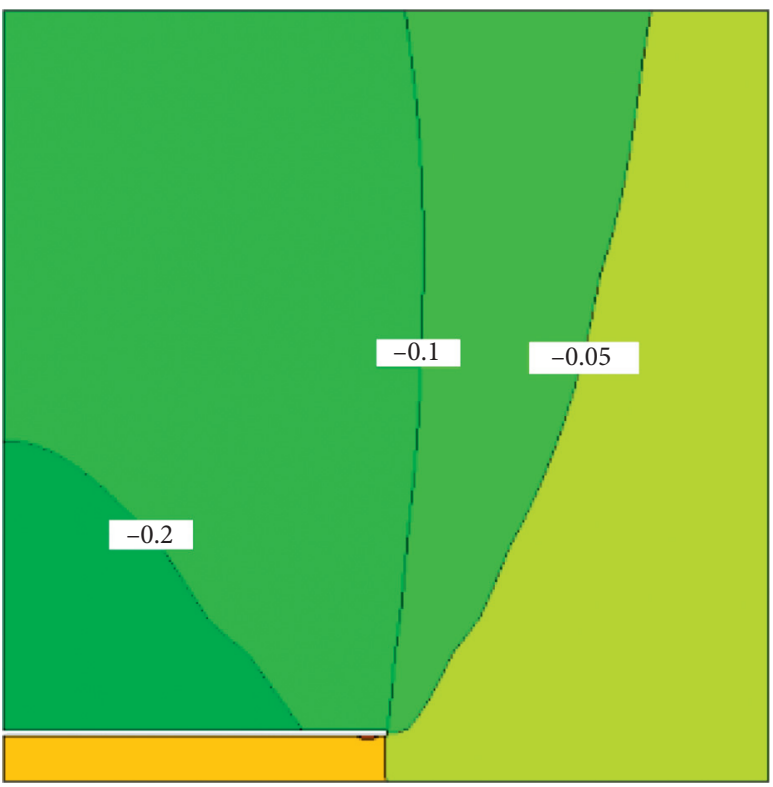

(c)

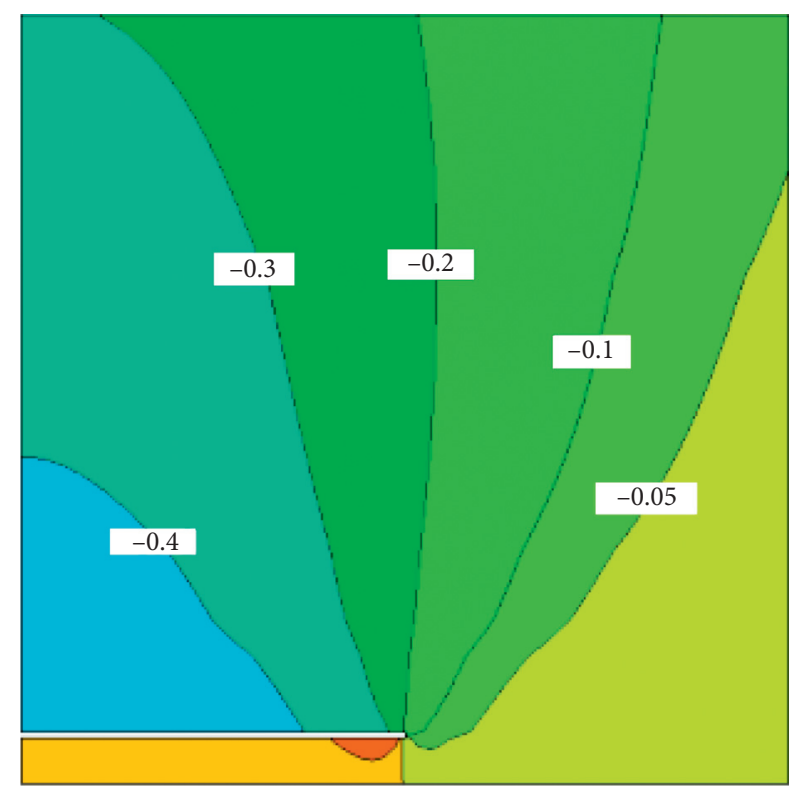

(b)

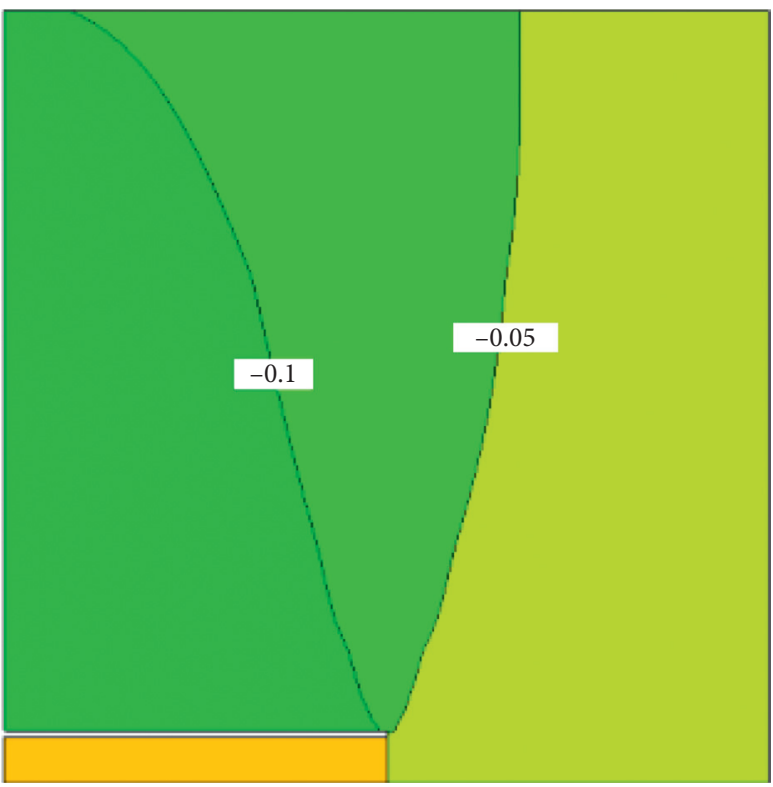

(d)

FIGURE 8: Contour map of vertical displacement of overburden at different initial compaction rates of backfill materials: (a) $\mathrm{K}_{\mathrm{ysini}}=0.95$; (b) $\mathrm{K}_{\mathrm{ysini}}=0.85$; (c) $\mathrm{K}_{\mathrm{ysini}}=0.75$; (d) $\mathrm{K}_{\mathrm{ysini}}=0.70$.

$600 \mathrm{~m}$, the $\mathrm{w}_{\mathrm{kmax}}$ of the key strata of overburden increases from $366.9 \mathrm{~mm}$ to $455.5 \mathrm{~mm}$, with an increase of $24.1 \%$. This increase range is obviously smaller than that of mining depth (71.4\%). In fact, with the increase of mining depth, the structure and lithologic composition of overburden have a great influence on the deformation of key strata of overburden, which is the main factor of overburden deformation resistance. Figures 11(b) and 11(c) show the surface subsidence curve of the model at different mining depths $H$, the variation curve of surface subsidence $\mathrm{w}_{\max }$ with mining depth $H$, and the variation curve of surface subsidence basin width $L$ with mining depth $H$. It can be seen that when the mining depth $H$ increases, the surface subsidence $\mathrm{w}_{\max }$ decreases slightly, because the greater the mining depth, the farther the stope is from the surface, and the less the influence of stress redistribution caused by mining on the surface. When the mining depth $H$ increases from $350 \mathrm{~m}$ to $600 \mathrm{~m}$, the surface subsidence $\mathrm{w}_{\max }$ decreases from $304.3 \mathrm{~mm}$ to $269.7 \mathrm{~mm}$, only decreasing by $34.6 \mathrm{~mm}$. It indicates that mining depth has little influence on surface subsidence. With the increase of mining depth, the dip angle of surface subsidence basin decreases, but the range of surface subsidence basin increases. When the mining depth $H$ increases from $350 \mathrm{~m}$ to $600 \mathrm{~m}$, the width of surface 


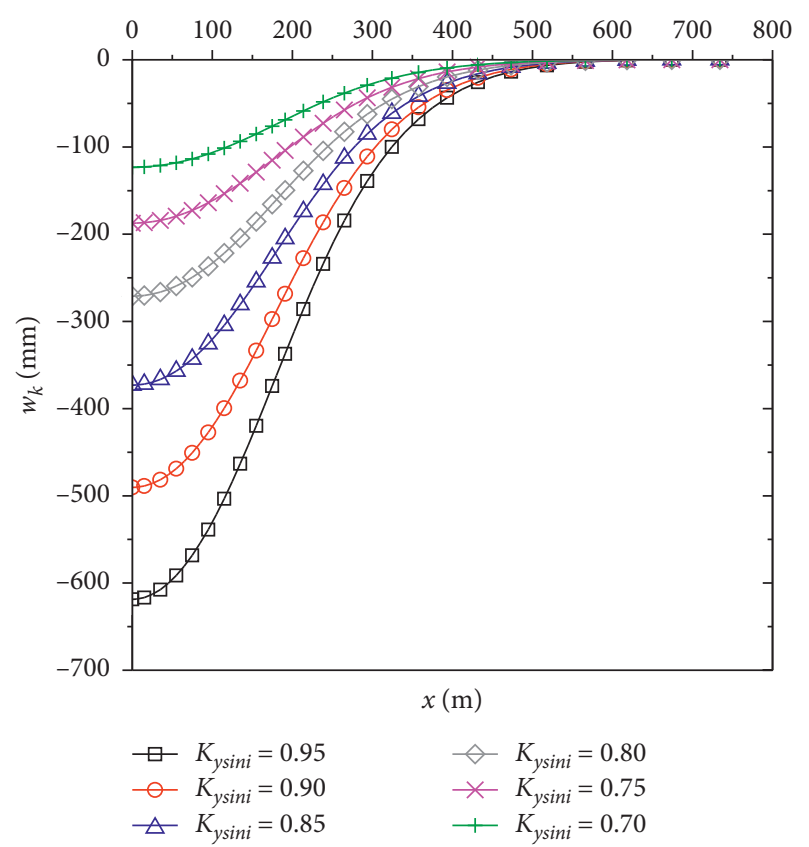

(a)

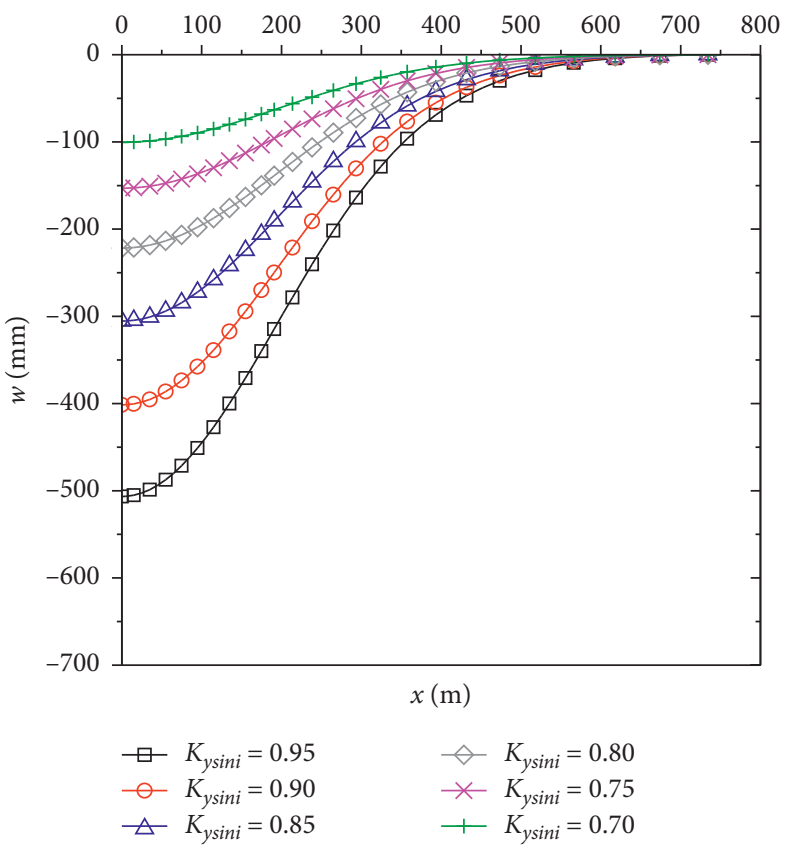

(b)

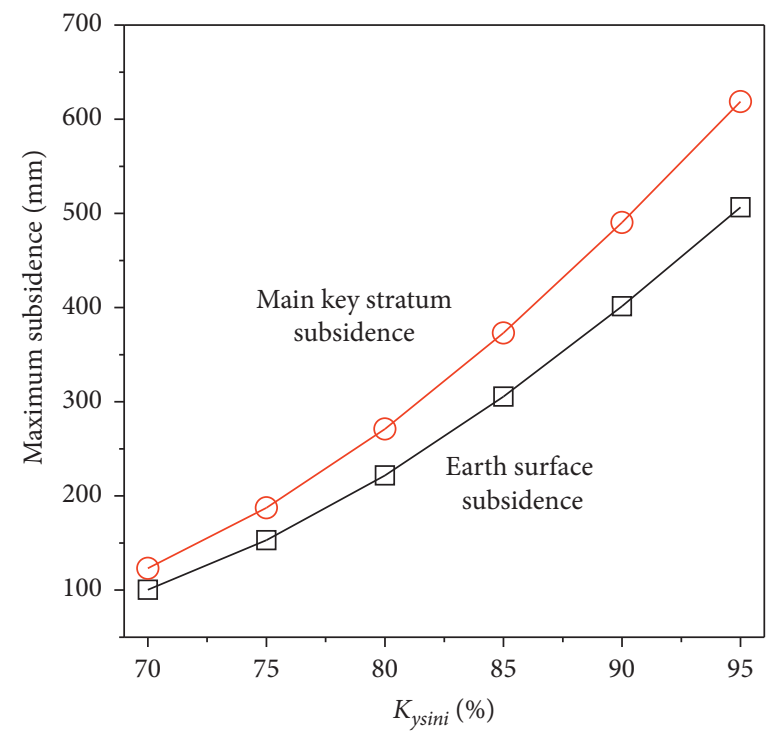

(c)

Figure 9: (a) Subsidence curve of main key strata, (b) surface subsidence curve, and (c) variation curve of maximum subsidence under different initial compaction rates.

subsidence basin $L$ increases from $1184 \mathrm{~m}$ to $1970 \mathrm{~m}$, with an increase of $66.4 \%$. It indicates that mining depth has a great influence on the surface subsidence range.

Figure 12 shows the contour map of vertical displacement of overburden at the different mining heights of the filling bod $(2.5-5.0 \mathrm{~m})$. In this figure, the horizontal dimension is $0 \mathrm{~m}-350 \mathrm{~m}$, that is, $350 \mathrm{~m}$ from the middle of the working face to the right, and the vertical dimension is $380 \mathrm{~m}$, that is, $380 \mathrm{~m}$ from the bottom of the model to the surface. Figure 13(a) shows the subsidence curve of the main key strata at different mining heights and the variation curve of the subsidence peak value of the main key strata with the mining height. It can be seen that with the increase of mining height, the contour lines of the same size gradually move to the upper part of the stope, and the deformation of the key strata of the overburden increases gradually. When the mining height $h$ increases from $2.5 \mathrm{~m}$ to $5.0 \mathrm{~m}$, the subsidence of the key strata of overburden increases from $267.4 \mathrm{~mm}$ to $530.2 \mathrm{~mm}$. It indicates that the mining height has a significant influence on the deformation of the key strata of the overburden. Figure 13(b) shows the surface subsidence curve of the model at different mining heights 


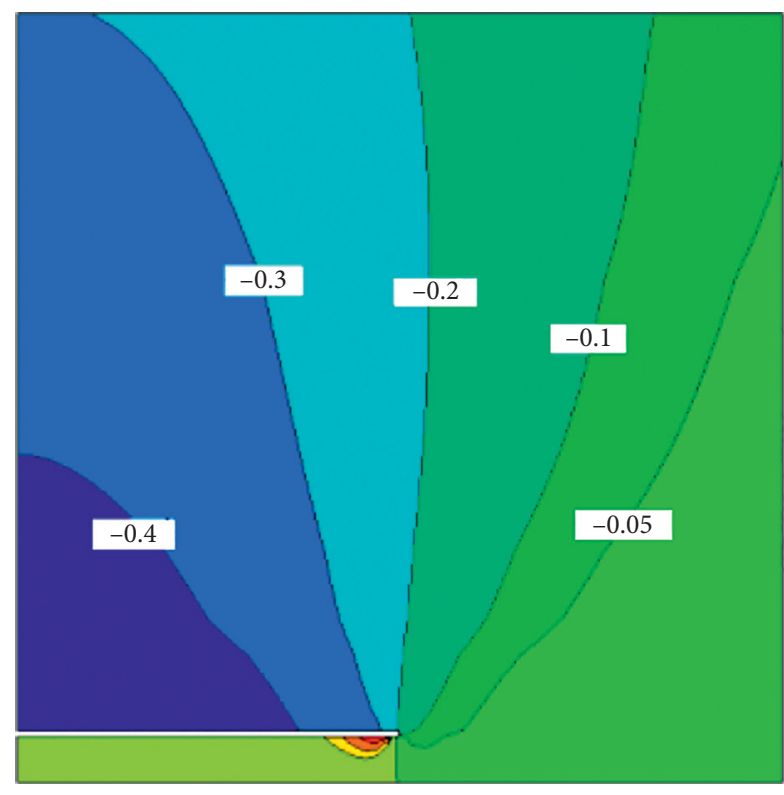

(a)

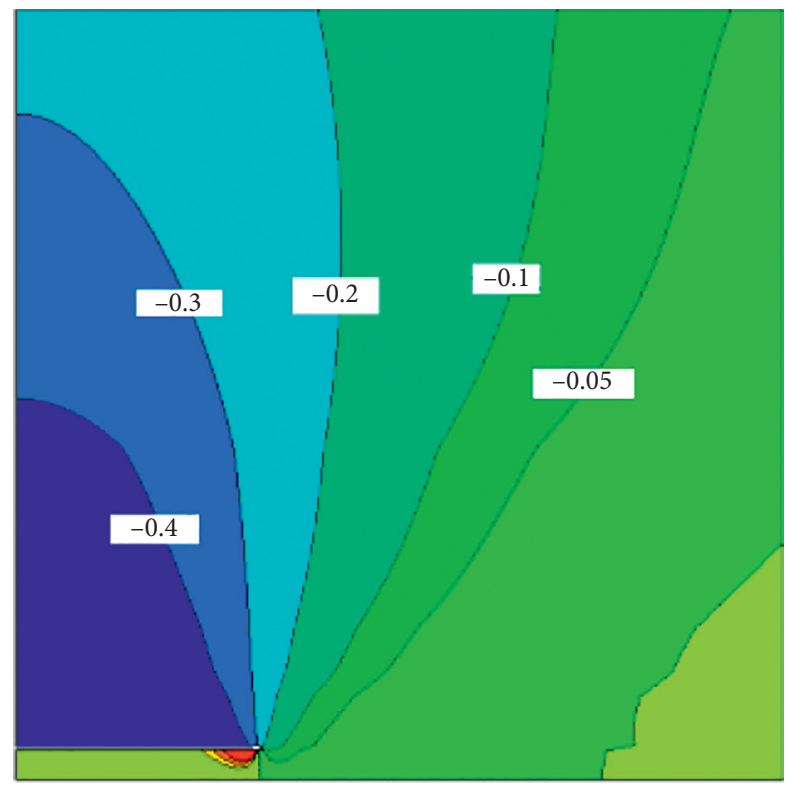

(c)

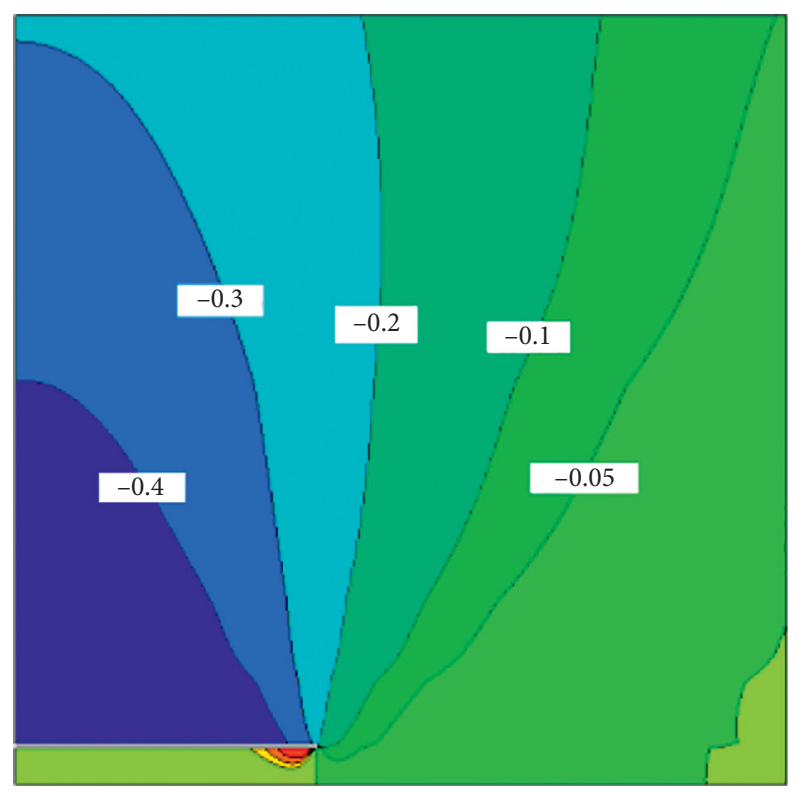

(b)

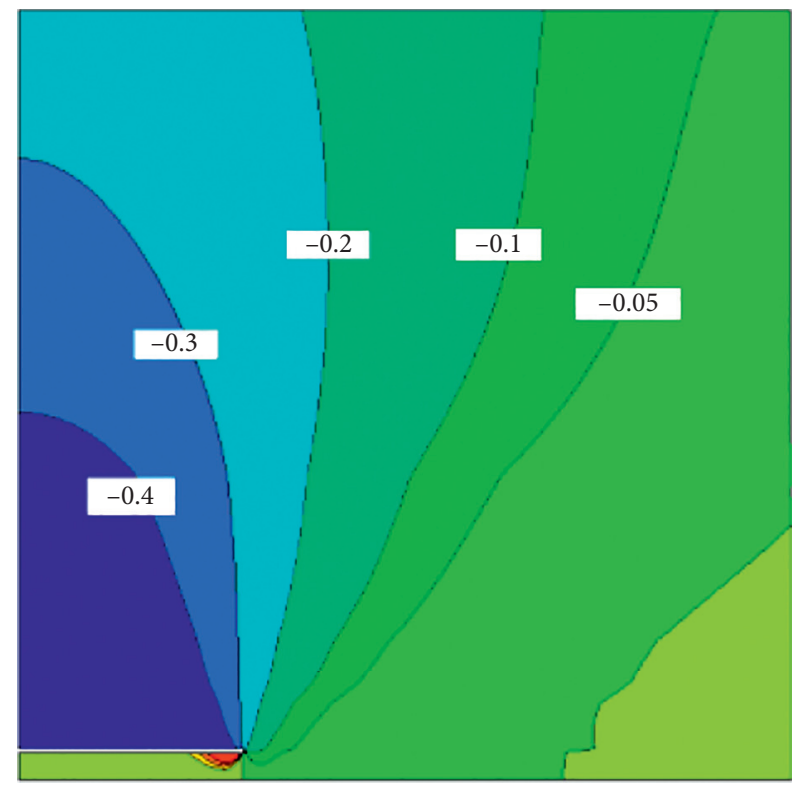

(d)

FIGURE 10: Contour map of vertical displacement of overburden in solid backfill mining at different mining depths: (a) $H=350 \mathrm{~m}$; (b) $H=450 \mathrm{~m}$; (c) $H=550 \mathrm{~m}$; (d) $H=600 \mathrm{~m}$.

and the variation curve of the peak value $\mathrm{w}_{\max }$ of surface subsidence with the mining height $h$. When the initial compaction rate of the filling body is 0.8 , the $\mathrm{w}_{\max }$ increases with the increase of mining height. Figure 13(c) shows the variation curves of the maximum subsidence of the surface and the main key strata with the mining height, both of which show a linear change law with the mining height.
When the mining height $h$ increases from $2.5 \mathrm{~m}$ to $6.0 \mathrm{~m}$, the $\mathrm{w}_{\max }$ increases from $218.9 \mathrm{~mm}$ to $434.0 \mathrm{~mm}$, indicating that the mining height has a significant impact on the surface subsidence in solid backfill mining. The surface subsidence is similar to the deformation law of the key strata of overburden, but its subsidence value is less than that of the main key strata. 


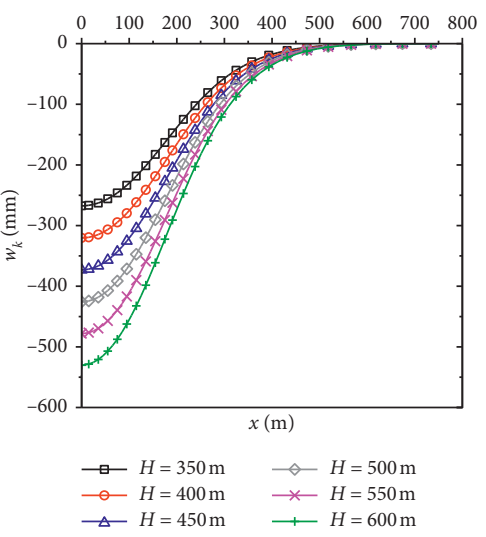

(a)

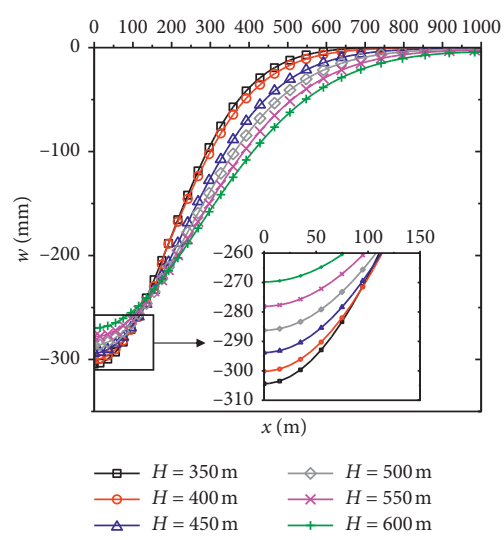

(b)

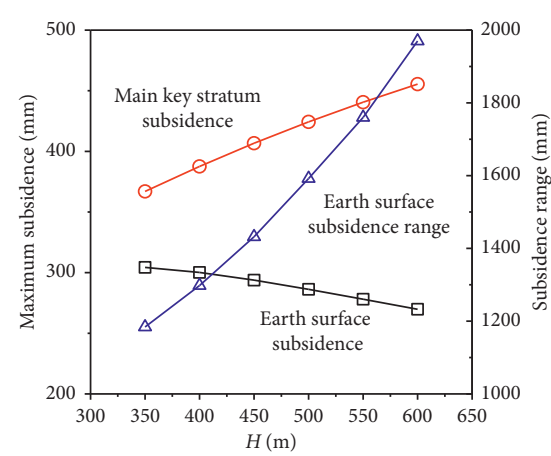

(c)

FIGURE 11: (a) Subsidence curve of main key strata, (b) surface subsidence curve, and (c) maximum subsidence and variation curve of surface subsidence range at different mining depths.

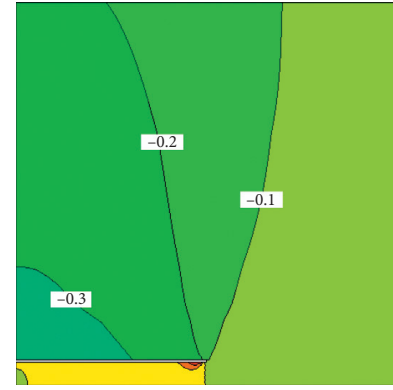

(a)

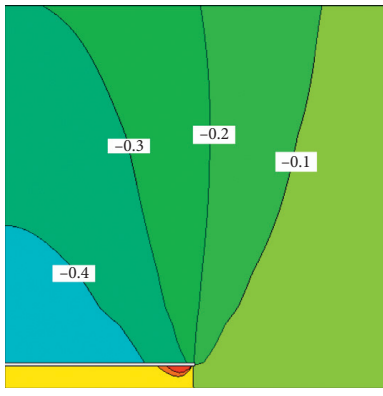

(b)

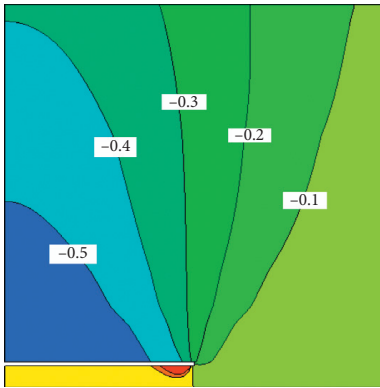

(c)

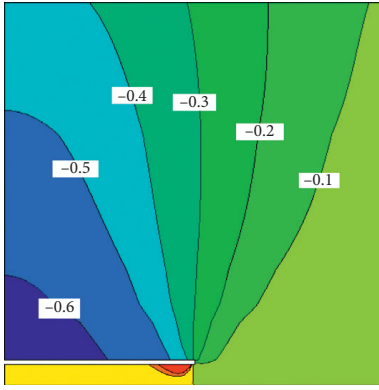

(d)

FIGURE 12: Contour map of vertical displacement of overburden at different mining heights: (a) $h=2.5 \mathrm{~m}$; (b) $h=3.5 \mathrm{~m}$; (c) $h=4.5 \mathrm{~m}$; (d) $h=5.0 \mathrm{~m}$.

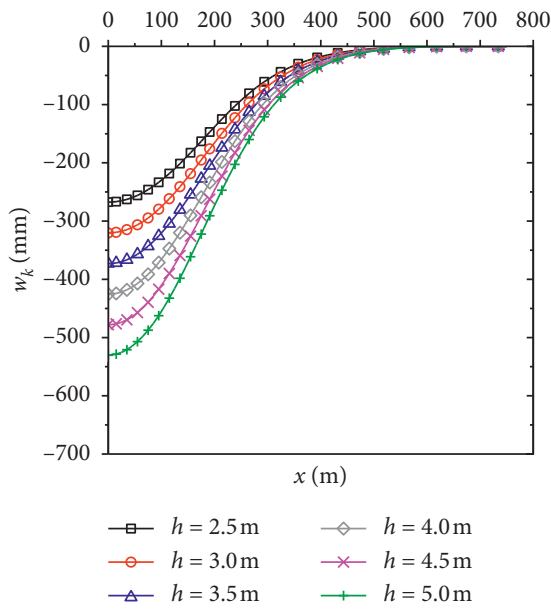

(a)

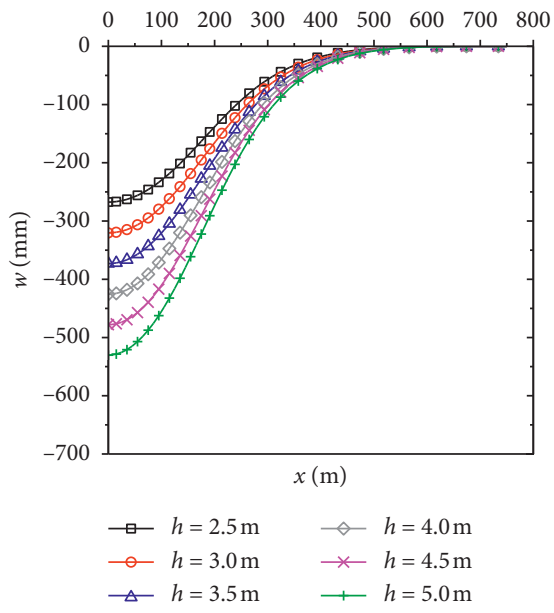

(b)

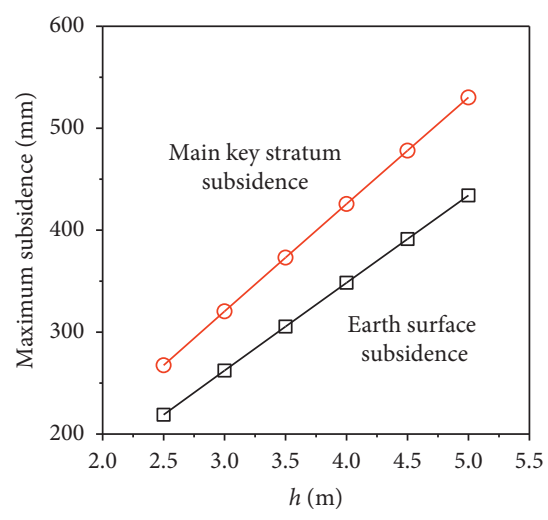

(c)

FIGURE 13: (a) Subsidence curve of main key strata, (b) surface subsidence curve, and (c) variation curve of maximum subsidence at different mining heights. 


\section{Conclusion}

(1) In this paper, the constitutive model of solid backfill materials based on elastic constitutive relation of solid material is proposed and used to accurately reveal the compaction mechanical characteristics of solid backfill materials. The ABAQUS UMAT subroutine, which is developed by the constitutive model, can be used to effectively predict the movement and deformation law of overburden in solid backfill mining;

(2) In solid backfill mining, the initial compaction rate and the height of coal seams have a significant impact on the surface subsidence. When the thickness of the topsoil is only changed and the structural composition and lithology of the overburden are not changed, the mining depth has little impact on the surface subsidence, but has a significant impact on the surface subsidence range;

(3) In solid backfill mining, the influence of mining height and mining depth on the deformation of key strata in the overburden and surface subsidence is approximately linear, but the influence of the initial compaction rate is nonlinear.

\section{Data Availability}

The data used to support the findings of this study are included within the article.

\section{Conflicts of Interest}

The authors declare that they have no conflicts of interest.

\section{Acknowledgments}

Ma Chao acknowledges the Key Research and Development Program of Xuzhou (no. KC20176). Zhang Lianying was supported by the National Natural Sciences Foundation of China (nos. 51974296 and 52074240), the Outstanding Innovation Team of Jiangsu Province (Safety of Engineering Structure under Complex Environmental), “333” Project of Jiangsu Province, the Key Research and Development Program of Xuzhou (no. KC18090), and the Innovation Capacity Building Program of Xuzhou (no. KC18241).

\section{References}

[1] M. Li, J. Zhang, W. Song, and D. M. Germain, "Recycling of crushed waste rock as backfilling material in coal mine: effects of particle size on compaction behaviours," Environmental Science and Pollution Research, vol. 26, no. 9, pp. 8789-8797, 2019.

[2] D. Ma, J. Zhang, H. Duan et al., "Reutilization of gangue wastes in underground backfilling mining: overburden aquifer protection," Chemosphere, vol. 264, no. 1, Article ID 128400, 2021.

[3] J. Zhang, F. Jiang, J. Yang, W. Bai, and L. Zhang, "Rockburst mechanism in soft coal seam within deep coal mines," International Journal of Mining Science and Technology, vol. 27, no. 3, pp. 551-556, 2017.
[4] M. Li, J. Zhang, A. Li, and N. Zhou, "Reutilisation of coal gangue and fly ash as underground backfill materials for surface subsidence control," Journal of Cleaner Production, vol. 254, Article ID 120113, 2020.

[5] N. Zhou, J. Zhang, S. Ouyang, X. Deng, C. Dong, and E. Du, "Feasibility study and performance optimization of sandbased cemented paste backfill materials," Journal of Cleaner Production, vol. 259, Article ID 120798, 2020.

[6] C. C. Zhou, G. J. Liu, D. Wu, T. Fang, R. W. Wang, and X. Fan, "Mobility behavior and environmental implications of trace elements associated with coal gangue: a case study at the Huainan Coalfield in China," Chemosphere, vol. 95, pp. 193-199, 2014.

[7] D. Ma, H. Duan, Q. Zhang et al., "A numerical gas fracturing model of coupled thermal, flowing and mechanical effects," Computers, Materials \& Continua, vol. 65, no. 3, pp. 21232141, 2020.

[8] Y.-H. Huang and S.-Q. Yang, "Mechanical and cracking behavior of granite containing two coplanar flaws under conventional triaxial compression," International Journal of Damage Mechanics, vol. 28, no. 4, pp. 590-610, 2019.

[9] D. Ma, J. Wang, X. Cai et al., "Effects of height/diameter ratio on failure and damage properties of granite under coupled bending and splitting deformation," Engineering Fracture Mechanics, vol. 220, Article ID 106640, 2019.

[10] D. Ma, H. Duan, X. Li, Z. Li, Z. Zhou, and T. Li, "Effects of seepage-induced erosion on nonlinear hydraulic properties of broken red sandstones," Tunnelling and Underground Space Technology, vol. 91, Article ID 102993, 2019.

[11] D. Ma, H. Duan, W. Liu, X. Ma, and M. Tao, "Water-Sediment two-phase flow inrush hazard in rock fractures of overburden strata during coal mining," Mine Water and the Environment, vol. 39, no. 2, pp. 308-319, 2020.

[12] A. Karaman, P. Carpenter, and C. Booth, "Type-curve analysis of water-level changes induced by a longwall mine," Environmental Geology, vol. 40, no. 7, pp. 897-901, 2001.

[13] Y. Yu and L. Ma, "Application of roadway backfill mining in water-conservation coal mining: a case study in northern Shaanxi, China," Sustainability, vol. 11, no. 13, p. 3719, 2019.

[14] J. Zhang, D. Li, and Y. Wang, "Predicting tunnel squeezing using a hybrid classifier ensemble with incomplete data," Bulletin of Engineering Geology and the Environment, vol. 79, no. 6, pp. 3245-3256, 2020.

[15] D. Turer, H. A. Nefeslioglu, K. Zorlu, and C. Gokceoglu, "Assessment of geo-environmental problems of the Zonguldak province (NW Turkey)," Environmental Geology, vol. 55, no. 5, pp. 1001-1014, 2008.

[16] Y. Li, S. S. Peng, and J. Zhang, "Impact of longwall mining on groundwater above the longwall panel in shallow coal seams," Journal of Rock Mechanics and Geotechnical Engineering, vol. 7, no. 3, pp. 298-305, 2015.

[17] J. Zhang, Q. Zhang, A. J. S. Spearing, X. Miao, S. Guo, and Q. Sun, "Green coal mining technique integrating miningdressing-gas draining-backfilling-mining," International Journal of Mining Science and Technology, vol. 27, no. 1, pp. 17-27, 2017.

[18] P. Huang, A. J. S. Spearing, J. Feng, K. V. Jessu, and S. Guo, "Effects of solid backfilling on overburden strata movement in shallow depth longwall coal mines in West China," Journal of Geophysics and Engineering, vol. 15, no. 5, pp. 2194-2208, 2018.

[19] M. Xiao, F. Ju, and Z.-q. He, "Research on shotcrete in mine using non-activated waste coal gangue aggregate," Journal of Cleaner Production, vol. 259, Article ID 120810, 2020. 
[20] G. Guo, W. Feng, J. Zha, Y. Liu, and Q. Wang, "Subsidence control and farmland conservation by solid backfilling mining technology," Transactions of Nonferrous Metals Society of China, vol. 21, pp. 665-669, 2011.

[21] Z. Bian, X. Miao, S. Lei, S.-e. Chen, W. Wang, and S. Struthers, "The challenges of reusing mining and mineral-processing wastes," Science, vol. 337, no. 6095, pp. 702-703, 2012.

[22] M. Li, J. X. Zhang, Z. Y. Wu, and K. Sun, "Calculation and monitoring analysis of stress distribution in a coal mine gob filled with waste rock backfill materials," Arabian Journal of Geosciences, vol. 12, no. 14, p. 418, 2019.

[23] M. Li, G. Meng, J. Zhang, P. Huang, and D. M. Germain, "Sensitivity analysis of key factors influencing compressioninduced deformation of waste rocks for backfilling to reduce environmental pollution," Environmental Science and Pollution Research, vol. 27, no. 14, pp. 16707-16717, 2020.

[24] M. Li, J. Zhang, G. Meng, Y. Gao, and A. Li, "Testing and modelling creep compression of waste rocks for backfill with different lithologies," International Journal of Rock Mechanics and Mining Sciences, vol. 125, Article ID 104170, 2020.

[25] Y. Huang, J. Li, D. Ma, H. Gao, Y. Guo, and S. Ouyang, "Triaxial compression behaviour of gangue solid wastes under effects of particle size and confining pressure," Science of The Total Environment, vol. 693, Article ID 133607, 2019.

[26] B. Y. Li, H. Yan, J. X. Zhang, and N. Zhou, "Compaction property prediction of mixed gangue backfill materials using hybrid intelligence models: a new approach," Construction and Building Materials, vol. 247, Article ID 118633.

[27] Y. L. Huang, J. X. Zhang, Q. Zhang, S. J. Nie, and B. F. An, "Strata movement control due to bulk factor of backfilling body in fully mechanized backfilling mining face," Journal of Mining and Safety Engineering, vol. 29, no. 2, pp. 162-167, 2012.

[28] J. F. Zha, G. L. Guo, Y. X. Liu, and B. Wu, "The nonlinear features of waste deformation and its impaction on strata movement," Journal of China Coal Society, vol. 34, no. 8, pp. 1071-1075, 2009.

[29] M. Li, J. X. Zhang, X. X. Miao, and Y. L. Huang, "Strata movement under compaction of solid back fill body," Journal of China University of Mining and Technology, vol. 43, no. 6, pp. 969-980, 2014.

[30] Q. Zhang, J. X. Zhang, Y. Chen, J. D. Ntigurirwa, and K. Q. Xia, "Moving set-up room theory of weakening the mining pressure caused by the backfilling body in solid backfilling mining," Energy Science and Engineering, vol. 8, no. 1, 2020.

[31] Z. G. Ma, Study on Compaction and Seepage Characteristics of Broken Rock in Goaf, China University of Mining and Technology Press, Xuzhou, China, 2009. 